\title{
Maximum ST Segment Elevation
}

National Cancer Institute

\section{Source}

National Cancer Institute. Maximum ST Segment Elevation. NCI Thesaurus. Code

C62160.

The maximum elevation of the ST segment, obtained from a set of measurements of the elevation of the ST segment. 